\title{
Assessing IUPUI's Diversity Scholars Research Program: Lessons Learned
}

\author{
Dominique M. Galli, Rafael Bahamonde, \\ Indiana University-Purdue University Indianapolis
}

\begin{abstract}
Launched in 1997, the Diversity Scholars Research Program (DSRP) is an undergraduate performance-based scholarship program that aims to attract academically talented, underrepresented minority (URM) students to the IUPUI campus. The program provides financial assistance (tuition, academic stipend, conference travel, and some housing), mentoring, professional development, and research support for up to four years. As of summer 2017, 65 percent of scholars in good standing have graduated from IUPUI. Four-year graduation rates of DSRP scholars were more than double the average graduation rates for URM students with comparable GPAs at admission. New initiatives have been implemented that include changes to the admission and selection process, additional support to first-year students, and improvement of communication between all stakeholders.
\end{abstract}

Keywords: assessment, diversity, graduation rate, scholarship, underrepresented minority students, undergraduate research

doi: 10.18833/spur/1/4/10

Studies of factors affecting college success show that students involved in undergraduate research are more likely to gain self-confidence, complete degrees, and go to graduate school than students without this experience (Boyd and Wesemann 2009; Linn et al. 2015). It has also been shown that undergraduate research improves retention and graduation rates of underrepresented minority (URM) students specifically (Nagda et al. 1998). In addition, it increases the likelihood that these students will continue on to pursue a graduate degree (Lopatto 2003; Seymour et al. 2004). The Indiana University-Purdue University Indianapolis (IUPUI) Diversity Scholars Research Program (DSRP) is an undergraduate performance-based scholarship program that encourages academically talented URM students to pursue an education in a research setting. The program goals include increasing the recruitment, retention, graduation, and workforce or graduate/professional school placement of URM students while simultaneously increasing the diversity of the IUPUI undergraduate student population. Learning through an independent undergraduate research project directed by a faculty mentor affords undergraduate students a unique opportunity to function at the cutting edge of an academic discipline. In addition, continued engagement in undergraduate research for up to four years strengthens their knowledge base and prepares them for competitive entry into graduate school or the workforce.

DSRP was founded in 1997 by the dean of the School of Science and was originally called the Minority Research Scholars Program (MRSP). At the time, it was the only IUPUI research program targeting URM students. The initial intent was to attract in-state URM students interested in a STEM education to IUPUI through direct contact with local high schools. Because of its success, MRSP received campus funding in 2003 to support and expand the program. In 2006, the program changed its name to DSRP, and its administration was transferred to the IUPUI Center for Research Learning (CRL). It is now open to students in all disciplines, although most scholars still major in STEM and health sciences disciplines. The number of scholarships in each discipline is determined by each participating academic unit (school) and is based on the 
school's commitment to cover the cost of tuition at the instate level. Over the years, admission to the program has been extended to out-of-state and international students. Currently the program accepts US citizens and permanent residents, with priority given to Indiana residents. The number of enrolled students per academic year has been in the range of 30 to 40 scholars in recent years.

\section{Program Features}

\section{Admission Criteria and Process}

DSRP accepts incoming first-, second-, and third-year students. Admission criteria are shown in Table 1. Incoming first-year students must be in the top 25 percent of their graduating high school class and accepted to IUPUI. Until fall 2016, the majority of students learned about DSRP through the CRL and Office of Student Scholarships (OSS) websites and recruitment events held by the Office of Undergraduate Admissions, as well as by word of mouth. DSRP applications were submitted directly to CRL and screened by the DSRP program manager. Now, all IUPUI scholarship applications are routed through AcademicWorks, an online platform at Indiana University. The process of selecting DSRP scholars is visualized in Figure 1. Students admitted to IUPUI are automatically notified of all available scholarships for which they qualify, including DSRP. Applications require the submission of a personal statement as well as two references through AcademicWorks. Subsequently, the DSRP program manager at CRL verifies the completeness of the application packages and forwards them to the academic units that correspond to the applicants' declared majors. Committees at the school level decide which students they wish to interview and accept to DSRP. The names are forwarded to CRL, and acceptance letters are sent. To facilitate communication between CRL and the schools, most academic units have a designated DSRP liaison (faculty or staff). The liaison is extremely important, as this individual is the primary contact for the DSRP program manager, who keeps the school updated on students' performance while they are in the program.

\section{Student Support}

The scholar's academic unit matches the student with a faculty mentor. Research mentors, who are IUPUI faculty members, help scholars design and carry out research projects during their tenure in the program. Usually, the student remains with the same mentor until graduation. Each year CRL disburses a small amount of supply money to mentors for use in students' projects. DSRP scholars receive financial support for payment of full in-state tuition and mandatory course fees (provided by the participating schools). Scholars also receive a DSRP stipend to cover other academic expenses in the fall and spring semesters, as well as a housing stipend if they choose to live in on-campus housing. Scholars have the option to participate in one of the CRL summer research programs and earn an additional summer stipend, in order to work on their DSRP projects or completely different projects. However, only a few DSRP scholars have taken advantage of this opportunity. The intent of DSRP is to fully engage scholars in all aspects of research while they pursue their undergraduate degrees. To this end, attendance of students at conferences to present their research projects and build networks is strongly encouraged. Unless a scholar is on probation, DSRP will cover all expenses incurred to present at a regional or national conference once a year. In addition, in fall 2016, a policy was implemented that required DSRP third- and fourth-year students to give an annual oral presentation at a local, regional, or national meeting. Similarly, since fall 2016, DSRP students have received a one-time reimbursement of fees for graduate and professional school admission exams if their scores are competitive.

\section{TABLE 1. Current DSRP Admission Criteria}

\begin{tabular}{|c|c|}
\hline $\begin{array}{l}\text { Incoming first-year } \\
\text { students }\end{array}$ & $\begin{array}{l}-\geq 1070 \text { old SAT score or } \geq 1140 \\
\text { new SAT score (math and critical } \\
\text { reasoning sections only), or } \geq 23 \\
\text { ACT score } \\
\text { - } \geq \text { cumulative high school GPA } 3.0 \\
\text { - references }\end{array}$ \\
\hline $\begin{array}{l}\text { Continuing IUPUI and } \\
\text { transfer students }\end{array}$ & $\begin{array}{l}\text { - } \geq \text { cumulative GPA } 3.3 \\
\text { - } \text { references } \\
\text { - } \text { previous research experience } \\
\text { - incoming second- or third-year } \\
\text { student }\end{array}$ \\
\hline
\end{tabular}

FIGURE 1. DSRP Applicant Selection Process
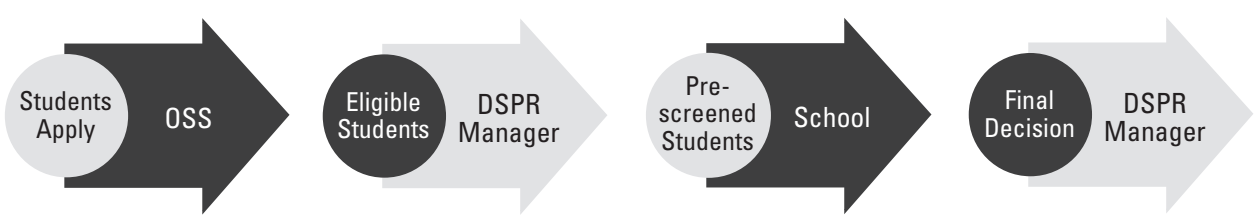

Note: The selection of scholars requires the collaboration of various parties, including the IU Office of Student Scholarship (OSS), the DSRP program manager at CRL, and participating schools, where the final selection of scholars is made. 


\section{Program Requirements}

DSRP scholars must engage in research for six to ten hours per week. This is monitored by the mentor and the unit liaison. The students present their research at least twice a year, on IUPUI Student Research Day in the spring and at the IU Undergraduate Research Conference in the fall. Since fall 2016, the drafting of a research project proposal at the start of each academic year, completion of a responsible conduct of research online module, submission of a research progress and final report (which includes a personal reflection essay), and completion of a program survey are mandatory requirements for all students. As students complete various annual benchmarks, the program provides progressive improvement in critical and analytical thinking, written and oral communication, and application and adaptation of knowledge. Qualitative and quantitative tools allow for assessment of student learning during the program. A mandatory professional development series enhances student preparedness for graduate or professional school and the workforce. Monthly topics include but are not limited to professional etiquette, time management, graduate or professional school preparation, financial literacy, and peer mentor training. At least twice per semester scholars are scheduled for one-on-one meetings with the DSRP program manager to discuss academic and research progress as well as other accomplishments and challenges. If needed, the program manager refers the scholar to other available resources and consultants on campus. A student with a semester GPA below 3.0 is put on probation. During the probationary period the student must continue to be fully engaged in research and meet all DSRP course requirements. A student with an overall GPA below 3.0 for two consecutive semesters will be dismissed from the program. Other reasons for dismissal include failing to engage in research on a regular basis and failing repeatedly to attend the monthly meetings, as well as proven allegations of research, academic, or personal misconduct. All program requirements and expectations are spelled out in a contract that is cosigned by student and mentor.

\section{Program Assessment}

Demographic, admission, and graduation data on URM students enrolled in DSRP at IUPUI from 1997 through 2017 were collected from CRL, OSS, and the Office of Institutional Research and Decision Support. Since its launch, DSRP has accepted 165 students. Interestingly, the 1997-2006 cohort was mainly composed of first-year students (54 out of 62 students). This number has since dropped to 52 percent (54 out of 103 students). As of today, the DSRP graduation rate is 65 percent (see Table 2 ). This number does not include IUPUI graduates who departed DSRP prematurely. Graduation rates have been higher in the past 10 years (70 percent) when compared to the first decade ( 60 percent). This is due to the difference in the number of enrolled first-year students. Retention and graduation rates of DSRP incoming first-year students were lower than those of scholars who joined the program at a later stage in their education. Indeed, 83 percent of scholars who were dismissed or voluntarily withdrew from the program had joined as first-year students (see Table 2). Most commonly, they were dropped from DSRP in the second year, after failing for two consecutive semesters.

Four- and six-year graduation rates of DSRP scholars were compared to those of URM students at IUPUI during the same time period. Since no complete institutional data sets were available for 2003-2005, this comparison was limited to 1997-2002 and 2006-2017 (see Table 3). Two cohorts of IUPUI students were included. URM peers were students admitted with the same GPA requirements as those for DSRP (a GPA of 3.0 or higher for first-year students and 3.3 or higher for transfer students). The second cohort was composed of all URM students enrolled

TABLE 2. Graduation and Dismissal Rates of DSRP Students

\begin{tabular}{|l|c|c|c|}
\hline & $\begin{array}{c}\text { Fall 1997- } \\
\text { Spring 2006 }\end{array}$ & $\begin{array}{c}\text { Fall 2006- } \\
\text { Spring 2017 }\end{array}$ & Total \\
\hline Total enrollments & 62 & $103^{\mathrm{a}}$ & 165 \\
\hline Total DSRP graduates & 37 & 53 & $90(65 \%)^{\mathrm{c}}$ \\
\hline Total dismissals and withdrawals & 25 & $23^{\mathrm{b}}$ & $48(35 \%)^{\mathrm{c}}$ \\
\hline First-year student enrollment & 54 & $54^{\mathrm{a}}$ & 108 \\
\hline First-year student graduates & 32 & 19 & $51(57 \%)$ \\
\hline $\begin{array}{l}\text { First-year student dismissals } \\
\text { and withdrawals }\end{array}$ & 22 & $18^{\mathrm{b}}$ & $40(83 \%)$ \\
\hline
\end{tabular}

Note: 27 are currently still enrolled in DSRP, of whom 18 joined as first-year students

${ }^{\mathrm{b}} 10$ students ( 7 of whom joined as first-year students) are still enrolled at IUPUI, and 5 students (all of whom joined DSRP as first-year students) eventually graduated from IUPUI, although not as DSRP scholars ${ }^{\mathrm{c} E x c l u d e s}$ current enrollees 
TABLE 3. Comparison of Time to Graduation between DSRP and URM Students at IUPUI

\begin{tabular}{|c|c|c|c|c|c|c|}
\hline & \multicolumn{2}{|c|}{ DSRP cohort } & \multicolumn{2}{|c|}{ IUPUI - URM peers ${ }^{a}$} & \multicolumn{2}{|c|}{ IUPUI - all URM } \\
\hline & 1997-2002 & 2006-2017 & 1997-2002 & 2006-2017 & 1997-2002 & 2006-2017 \\
\hline$\leq 4$ years $^{\text {b }}$ & $29 \%$ & $68 \%$ & $12 \%$ & $25 \%$ & ND & $13 \%$ \\
\hline$\leq 6$ years $^{\mathrm{b}}$ & $62 \%$ & $78 \%$ & $54 \%$ & $39 \%$ & ND & $36 \%$ \\
\hline $\begin{array}{l}\text { First-year students } \leq 4 \\
\text { years }\end{array}$ & $29 \%$ & $60 \%$ & $12 \%$ & $29 \%$ & $1.4 \%$ & ND \\
\hline $\begin{array}{l}\text { First-year students } \leq 6 \\
\text { years }\end{array}$ & $62 \%$ & $63 \%$ & $54 \%$ & $44 \%$ & $32 \%$ & ND \\
\hline
\end{tabular}

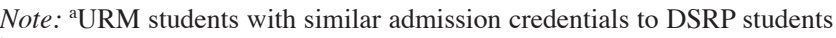

bincludes incoming first-year and transfer students for the 2006-2017 cohorts and first-year students only for the 1997-2002 cohorts ND: not determined

at IUPUI, regardless of GPA. Not surprisingly, graduation rates were much higher for DSRP scholars than for either IUPUI cohort. Particularly, the four-year graduation rates were more than twice as high for both first-year students and continuing or transfer students, clearly demonstrating the significant impact of DSRP.

Of the 53 DSRP students who graduated from IUPUI in the past 11 years, 23 (43 percent) enrolled in graduate or professional programs, with 14 of them remaining at IUPUI and its affiliated professional schools, 6 continuing their studies at universities in Indiana, and 3 going to outof-state institutions. Until 2016, the graduate and professional school enrollment was 58 percent. The recent drop in percentage is due to the fact that only 5 students $(28$ percent) of the 2017 cohort are pursuing postbaccalaureate studies. However, during the exit interviews several of the recent graduates indicated that they intend to apply to graduate or professional programs after spending a year or more in the workforce.

\section{Lessons Learned}

The program assessment data clearly indicate that incoming first-year students are less likely to remain in DSRP. Although record keeping through 2015 was inconsistent, it appears that most program dismissals were due to poor academic performance (failure to maintain a GPA of 3.0 or higher). In the past two years, students voluntarily withdrawing from DSRP expressed a desire to focus on coursework (2 students) and preemptively dropped out of the program due to pending dismissal (2 students).

Structured interviews, writing assignments such as annual reflective essays, and annual program surveys were first introduced in the 2016-2017 academic year. The sample size is currently too small to allow formal data analysis. However, anecdotal evidence gathered indicates that many incoming first-year students are struggling to balance academic coursework with the demands of doing research. Preliminary data show that these students do not understand the time commitment needed for research and carry course loads that are too large, with the latter often mandated by their disciplines. Personal essays describe challenges related to time management, self-motivation, organization, and-in one case-imposter syndrome. During regular meetings with the DSRP program manager, students often did not disclose that their grades were dropping but rather insisted that they were "doing fine." Adding to the problem was the fact that some schools did not identify research mentors until late in the fall semester. Some mentors lacked experience or were unfamiliar with DSRP requirements and so did not provide the necessary support. The new requirement of submitting annual proposals and reports to monitor research progress raised additional issues. Even at the third- and fourth-year levels, many students displayed poor scientific writing skills in these proposals and reports. Several students failed to act professionally. They did not adhere to deadlines set for report submissions and repeatedly skipped monthly group meetings and one-on-one meetings with the DSRP program manager. One might place blame on the faculty mentors for a lack of involvement in students' academic and professional development. Indeed, data from the first student survey last year showed that 4 of 11 participants who were either first- or second-year students expressed dissatisfaction with the mentoring experience. However, most of these faculty members are already overextended with mentoring of various undergraduate students in research, with little or no reward or acknowledgment at the school or campus level. In fact, many faculty mentors have been involved with DSRP for many years and continue to accept new students, significantly contributing to the success of the program. Unfortunately, the academic reward system at research-intensive universities often fails to value these undergraduate student mentors (Lopatto 2010). 


\section{Recent Program Changes}

At the start of the 2017-2018 academic year, various initiatives were implemented to address lingering program issues.

\section{Admission Criteria and Selection}

To identify students genuinely interested and qualified to engage in research, a more stringent admission and selection process was implemented. Applicants are expected to write an essay in which they reflect on their interest in research and its role in their education and future career path, instead of the more generic personal statement submitted in the past. Basic letters of support have been replaced by reference forms that assist with assessment of a student's capability to engage in research successfully. High school teachers score the applicant's intellectual curiosity, emotional maturity, communication skills, perseverance, selfmotivation, dependability, and level of confidence.

\section{Student Support}

Most important, first-year students have to be set up for success by provision of additional resources and support. Schools are expected to start identifying potential mentors in the spring, immediately following the selection and acceptance process. The incoming cohort is required to attend a two-week summer program prior to the start of the academic year. Activities include an introduction to program requirements, professional behavior, team building, and time management and a meeting with third- and fourthyear DSRP students who share their personal experiences, particularly with respect to overcoming early challenges. In addition, new scholars now receive a student handbook describing all program expectations, policies, and forms. Students new to DSRP have to enroll in a basic scientific and technical writing course that runs for two semesters and was developed specifically for DSRP students. The course kicks off during the summer program with an in-class session and is subsequently taught online. Mentors assist students with reading and writing assignments, and peers are asked to provide constructive writing feedback. Firstyear students are no longer expected to start actual research projects during the fall semester. Instead, their faculty mentors introduce them to literature in the field and teach them the quantitative and qualitative methods common in their disciplines. Students then launch their projects in the spring semester. In addition, students who struggle in their courses are immediately matched with DSRP peer mentors in their disciplines. DSRP third- and fourth-year students willing to serve as mentors have already been identified and undergone appropriate training. They are recognized as DSRP leaders at the end of each academic year.

\section{Mentor Support}

In the past, CRL offered mentoring workshops that were poorly attended. In 2017, a mentor guidebook was assembled to convey program expectations. The guidebook addresses best practices in student mentoring, including the mentoring of URM students, and provides a list of available resources. Mentors who ask for assistance are matched with experienced peer mentors.

\section{Accountability}

Each semester, for as long as they are in the program, all DSRP scholars have to enroll in the 0-credit DSRP course. The course appears on the student's transcript. To pass the course they need to complete the various assignments, such as research proposals and reports, by the stated deadlines; continually engage in research that is monitored by the DSRP program manager through regular communication with the faculty mentor; and attend the monthly seminars. A student who fails the course is put on probation. Failing the course twice results in dismissal.

\section{Conclusion}

Data clearly demonstrate that DSRP has met its stated goals. DSRP graduation rates are significantly higher than those of peer groups at IUPUI, and close to half of DSRP students enroll in postbaccalaureate programs immediately following graduation. The overall success of the program can be attributed to the strong commitment of academic deans and senior campus administrators who provide both financial and administrative support; housing of the program at CRL, a unit dedicated to undergraduate research; dedicated faculty mentors; and scholars willing to work hard and overcome personal challenges to accomplish their goals. To improve the program and particularly increase retention and graduation rates, DSRP first-year students are now offered additional support, and measures are taken to ease them into the research experience. Finally, communication with all stakeholders, including students, faculty mentors, and school liaisons, continues to improve and remains crucial to the continued success of the scholars.

\section{References}

Boyd, Mary K., and Jodi L. Wesemann (eds). 2009. Broadening Participation in Undergraduate Research: Fostering Excellence and Enhancing the Impact. Washington, DC: Council on Undergraduate Research.

Linn, Marcia C., Erin Palmer, Anne Baranger, Elizabeth Gerard, and Elisa Stone. 2015. "Undergraduate Research Experiences: Impacts and Opportunities." Science 347: 1261757. doi: 10.1126/ science. 1261757

Lopatto, David. 2003. "The Essential Features of Undergraduate Research.” CUR Quarterly 23(3): 139-142.

Lopatto, David. 2010. Science in Solution: The Impact of Undergraduate Research on Student Learning. Washington, DC: Council on Undergraduate Research.

Nagda, Biren A., Sandra R. Gregerman, John Jonides, William von Hippel, and Jennifer S. Lerner. 1998. "Undergraduate Student-Faculty Partnerships Affect Student Retention." Review of Higher Education 22: 55-72. doi: 10.1353/rhe.1998.0016 
Seymour, Elaine, Anne-Barrie Hunter, Sandra L. Laursen, and Tracee D. Antoni. 2004. "Establishing the Benefits of Research Experiences for Undergraduates in the Sciences: First Findings from a Three-Year Study." Science Education 88: 493-534. doi: $10.1002 /$ sce. 10131

Dominique M. Galli

Indiana University-Purdue University Indianapolis, dgalli@iu.edu

Dominique M. Galli is IUPUI assistant vice chancellor for research and executive director of the Center for Research and Learning. In the latter role she oversees various undergraduate research programs, including the Diversity Scholars Research Program. She also serves on the leadership team of the NIH IUPUI Graduate Preparation for the Biomedical and Behavioral Sciences program. Galli has a PhD in microbiology and is a faculty member in the Department of Biomedical and Applied Sciences.

Rafael Bahamonde is acting dean of the School of Health and Human Sciences and professor in the Department of Kinesiology at IUPUI. Bahamonde was director of the Diversity Scholars Research Program at IUPUI and has been involved as a mentor in federal and university programs such as LSAMP, the McNair Scholars Program, $U R O P, S R O P$, and HBCU. He currently is a member of the leadership teams of the NSF-funded Louis Stokes Midwest Center for Excellence and the NIH IUPUI Graduate Preparation for the Biomedical and Behavioral Sciences program.

\section{Coming up in SPUR...}

Fall 2018: "Mentoring Models"

Winter 2018: General Issue

Spring 2019 and Summer 2019:

"Big Data as a Tool to Promote

Undergraduate Research"

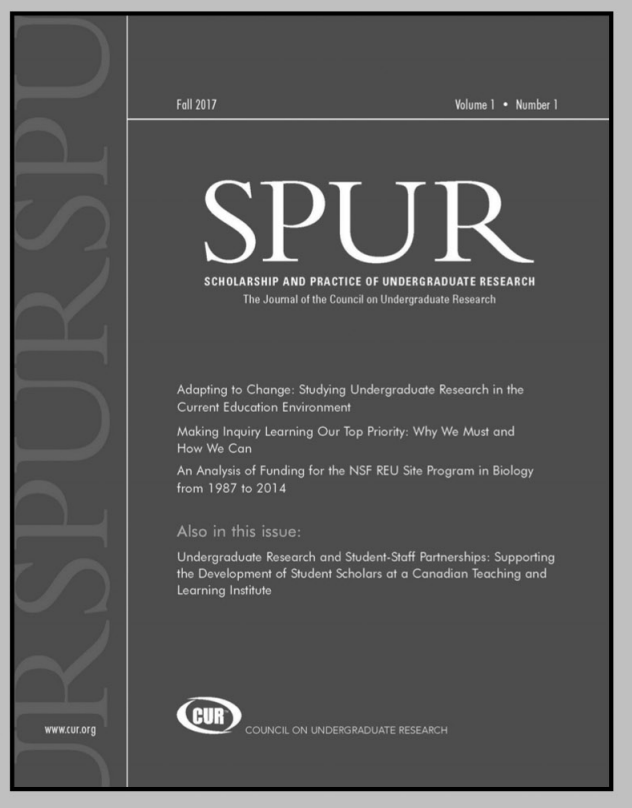

